\title{
ATITUDES E COMPORTAMENTOS DOS TRABALHADORES FACE ÀS TRANSFORMAÇÕES DO MUNDO DO TRABALHO SEGUNDO O MARXISMO ANALIITICO OU INDIVIDUALISMO METODOLÓGICO
}

\author{
ATTITUDES AND BEHAVIORS OF WORKERS IN RELATION \\ TO THE TRANSFORMATIONS OF WORLD OF WORK ACCORDING \\ TO THE ANALYTICAL MARXISM OR METHODOGICAL INDIVIDUALISM
}

Noêmia Lazzareschi*

\begin{abstract}
Resumo
Este artigo tem como objetivo demonstrar que as atitudes e os comportamentos políticos, isto é, as estratégias de ação política dos trabalhadores para a defesa de seus interesses e a realização de suas expectativas, em todos os países industrializados do Ocidente, expressam clara compreensão do contexto histórico no qual surgem novas condições objetivas de trabalho e novas condições materiais de vida. Pretende-se, portanto, demonstrar, com fundamento na extensa bibliografia nacional e internacional sobre o mundo do trabalho e, especificamente, sobre o movimento sindical, que os trabalhadores elaboram formas de resistência que resultam de uma análise racional das condições dadas e das possibilidades de realização de seus objetivos e expectativas pessoais ou coletivos, a partir da qual tomam decisões estratégicas que definem o rumo de sua própria história. Assim, trata-se de se acompanhar, tal como indica o seu título, as atitudes e comportamentos dos trabalhadores face às transformações do mundo do trabalho que tipificaram as últimas décadas do século XX e estão revolucionando as primeiras décadas deste século, graças à utilização da inteligência artificial, blockchain, big data e profusão de aplicativos para a satisfação de um sem número de necessidades sociais, com a finalidade de indicar que resultaram sempre de uma escolha racional alternativas existentes, definindo a configuração da estrutura social da qual são os sujeitos.

Palavras-chave: Atitudes e comportamentos políticos. Estratégias de ação política. Formas de resistência. Escolha racional.
\end{abstract}

\begin{abstract}
This article aims to demonstrate that political atitudes and behaviors, that is, the strategies of political action of workers to defend their interests and realize their expectations, express a clear understanding of the historical context in which new working conditions and new material conditions of life arise. It is intended, therefore, to demonstrate that workers develop forms of resistance that result from a rational analysis of the given conditions and the possibilities of achieving their personal or collective objectives and expectations, from which they make strategic decisions that define the course of theis own history. Thus, it is a question of accompanying, as its title indicate, the atitudes and behaviors of workers in the face of the transformations of the world of work that typified the last decades of the twentieth century and are revolutionizing the first decades of this century, thanks to the use of artificial intelligence, blockchain, big data and the profusion of applications to satisfy a number of social needs, in order to indicate that they resulted from a rational choice of existing alternatives, defining the configuration of the social structure of which the subjects are.
\end{abstract}

Keywords: Political attitudes and bevahiors. Interests and expectations of workers. Forms of resistance. Rational choice.

\footnotetext{
* Bacharela e licenciada em Ciências Sociais pela USP; mestra em Ciências Sociais do Trabalho pelo Institut Supérieur du Travail da Université Catholique de Louvain, Bélgica; doutora em Ciências Sociais pelo Instituto de Filosofia e Ciências Humanas da Unicamp; profa. da Faculdade de Ciências Sociais e do Programa de Estudos Pós-Graduados em Ciências Sociais da PUC-SP. E-mail: acyr.noemia@terra.com.br
} 

do trabalho segundo o marxismo analítico ou individualismo metodológico

\section{Introdução}

A análise do tema proposto parte do pressuposto de que as transformações das condições objetivas de trabalho e das condições materiais de vida dos trabalhadores, como também as transformações mundiais, alteram as percepções subjetivas da realidade vivida e fundamentam, em decorrência, novos comportamentos políticos, isto é, novas estratégias de ação política. Por isso, pretende-se acompanhar a introdução de novas tecnologias e de novas técnicas de gerenciamento do processo de trabalho que revolucionam as formas de organização da produção e da prestação de serviços e fazem surgir novas formas, individuais e coletivas, de resistência dos trabalhadores, para compreendê-las como fruto do estabelecimento das devidas conexões entre condições objetivas de trabalho e perspectivas de realização dos interesses individuais e coletivos que perseguem.

No entanto não se abraça aqui a tese do determinismo tecnológico. Ao contrário. $\mathrm{O}$ simples fato de se querer conhecer as formas de resistência do trabalhador frente as novas condições de trabalho já é o bastante para reafirmar que a tecnologia não é neutra e, portanto, a base material do capitalismo é capitalista. A intenção deste estudo é, pois, a de considerar determinadas condições tecnológicas como uma das variáveis mais importantes na determinação do comportamento político dos trabalhadores, dentro e fora das unidades produtivas, exatamente pelo fato de se constituírem no fator mais imediatamente perceptível pelo trabalhador para a identificação do grau de intensidade do poder de resistência que detém em suas mãos e, daí, no fator decisivo do modo de elaboração de suas práticas reivindicativas e do significado mesmo de sua condição social.

Uma outra preocupação deste estudo é a de abordar o desenvolvimento tecnológico e as técnicas de gerenciamento do processo de trabalho, o modo de sua utilização no processo produtivo e da prestação de serviços, isto é, a organização do trabalho, as formas de gestão da força de trabalho e as formas de resistência dos trabalhadores, tal como as demais variáveis que entram na determinação da totalidade do social, como resultado de uma escolha pensada e efetivada pelos sujeitos históricos dentre o conjunto de alternativas que o processo histórico, fruto de estruturas de escolhas anteriores e estrutura de escolhas futuras, a cada momento torna possíveis.

Assim, a configuração do interior das unidades de trabalho e a orientação política dos movimentos sindicais serão tratados como resultado de decisões elaboradas a partir do desenvolvimento de uma análise racional das condições dadas e das possibilidades, nessas condições, de realização dos interesses das partes envolvidas. Com isso, pretende-se afastar da análise todos os tipos de determinismos que têm obstaculizado a compreensão da história, ao fornecer explicações que imputam a entidades abstratas - a estrutura, o capital, a tecnologia - a sua produção, impossibilitando a identificação de seus sujeitos. 
E, no entanto, este é um fato inelutável: indivíduos, seres humanos, pessoas, com suas motivações, interesses, preferências, crenças, atitudes e comportamentos são os produtores da história. Produzem-na, é verdade, em condições dadas: nas condições produzidas e legadas por outros indivíduos, a partir das quais deliberam acerca de suas próprias vidas, criando novas condições de acordo com as escolhas de alternativas que puderam efetivar. Esquecer desse "detalhe" significa sobrepor a investigação e o conhecimento das necessidades ou imperativos da estrutura das condições objetivas à investigação e conhecimento das ações dos homens na estrutura, por eles mesmos produzida e, em consequência, para parafrasear Thompson, enveredar-se "num planetário de erros" - como indica o título de seu trabalho "A miséria da teoria ou um planetário de erros", de 1978 -, dentre eles o determinismo tecnológico inerente ao determinismo econômico e a todos os tipos de reducionismo.

Isso tudo significa que neste estudo a apresentação das formas de resistência dos trabalhadores às condições de trabalho e de vida tem como fundamento o esquema teórico desenvolvido por Olson, Cohen, Elster, Roemer, Adam Przeworski e que se convencionou denominar de individualismo metodológico ou marxismo analítico. Pelos seus pressupostos, o marxismo analítico ou individualismo metodológico permite estabelecer as relações entre estrutura e sujeito na história e sociedade humana e, em especial, permite demonstrar que a parceria ou colaboração capital/trabalho, impensável segundo o esquema teórico marxista, a não ser como fruto do processo de imposição da ideologia da classe dominante e, portanto, como alienação, é resultado de decisões estratégicas de ambas as partes na busca da realização de seus interesses e aspirações enquanto indivíduos e enquanto grupos de interesses, apesar de, no limite, esses interesses coincidirem, após uma avaliação racional das alternativas de escolhas de comportamento nas condições dadas.

As relações sociais estabelecem estruturas de escolhas segundo as quais as pessoas percebem, avaliam e agem. As pessoas consentem quando escolhem determinadas linhas de ação e quando seguem na prática essas escolhas. Os assalariados dão seu consentimento à organização capitalista da sociedade quando agem como se fossem capazes de melhorar suas condições materiais dentro dos limites do capitalismo. Mais especificamente, consentem quando agem coletivamente como se o capitalismo fosse um jogo de soma positiva, ou seja, quando cooperam com os capitalistas ao escolher suas estratégias (PRZEWORSKI, 1989, p. 175).

Em outras palavras, a estrutura social se mantém se puder oferecer às pessoas, enquanto indivíduos e enquanto membros de vários grupos, alguma garantia de que seus interesses, pelo menos parcialmente, serão realizados, o que implica afirmar que o consentimento e a colaboração são sempre provisórios porque a avaliação racional das condições dadas em função das possibilidades de realização de interesses é permanente. 

do trabalho segundo o marxismo analítico ou individualismo metodológico

Assim, as decisões são estratégias de ação política de cujos resultados não só dependem a realização dos objetivos e expectativas pessoais ou coletivos dos trabalhadores, como também a configuração da estrutura social da qual são os sujeitos. Isto é: esta perspectiva de análise enfatiza a capacidade de os indivíduos procederem a escolhas racionais dentre as alternativas oferecidas pelas condições dadas, do mesmo modo produzidas pelas gerações anteriores, de acordo com a "experiência", no sentido de Thompson, que dela tem e da qual nascem as suas crenças, motivações e interesses por cuja realização se luta na história. Lembre-se que para Thompson (1978, p. 15),

...experiência - uma categoria que, por mais imperfeita que seja, é indispensável ao historiador, já que compreende a resposta mental e emocional, seja de um indivíduo ou de um grupo social, a muitos acontecimentos inter-relacionados ou a muitas repetições do mesmo tipo de acontecimento.

\section{Transformações na organização do processo de trabalho e movimento sindical nos países industrializados do Ocidente}

Os sindicatos só puderam garantir a sua existência institucionalizada como organizações livres e soberanas de representação dos interesses, tanto da classe trabalhadora quanto da classe patronal, nas democracias políticas da Europa, apenas na segunda metade do século XIX. São frutos da consolidação do modo de produção capitalista do qual emerge o conflito de classes, e do Estado Moderno, que se fundamenta na igualdade jurídica de seus cidadãos, na liberdade de expressão e na liberdade de associação para a representação de seus interesses, seja em sindicatos, seja em partidos políticos, que disputam o poder e garantem a sua alternância.

Os sindicatos do século XIX nasceram revolucionários, pois lutavam pelo fim da propriedade privada dos meios de produção, ou seja, contra o regime de produção capitalista e, em consequência, para libertar os trabalhadores dos grilhões da economia de mercado, isto é, da exploração do trabalho pela extração da mais-valia. Nasceram, portanto, com orientação ideológica socialista e comunista, como organizações espontaneamente criadas e sustentadas por seus filiados.

$\mathrm{Na}$ Europa, os primeiros sindicatos eram constituídos de trabalhadores profissionalmente qualificados, ex-artesãos, que perderam a propriedade de seus instrumentos de trabalho e dos frutos de seu trabalho e tornaram-se assalariados das grandes oficinas. Eram marceneiros, pedreiros, pintores etc. e fundaram os sindicatos de ofício com grande poder de barganha, pois detinham o controle do processo de trabalho em seus locais de trabalho.

Trabalhadores não qualificados ou semiqualificados pertenciam aos sindicatos formados por setor de produção, isto é, por ramo industrial, dando origem ao sindicalismo de indústria. $\mathrm{Na}$ Inglaterra, trabalhadores não qualificados filiavam-se aos sindicatos gerais que agrupavam várias profissões ou ramos industriais e que, segundo Eric Hobsbawn (1964, p. 179), 
preencheram, às vezes simultaneamente, três funções bastante diferentes: como "sindicatos de classe" (class-unions), tentaram unir todos os empregados contra os empregadores, geralmente sob inspiração socialista ou revolucionária. Como "sindicatos de trabalhadores não qualificados" (labourers unions) tentaram oferecer uma efetiva organização para trabalhadores sem condições de integrar o sindicalismo de ofício ortodoxo, ou dele excluídos. Como "sindicatos residuais" (residual unions), finalmente, organizaram trabalhadores não efetivamente cobertos por outros sindicatos.

Já na segunda metade do século XIX, os movimentos sindicais dos trabalhadores obtiveram como conquista fundamental a promulgação da legislação trabalhista em vários países europeus para a regulamentação das relações de trabalho, graças à pressão sobre o Estado e sobre a classe patronal, com total apoio da Igreja Católica Apostólica Romana, por meio da publicação da encíclica Rerum Novaram do Papa Leão XIII. Considere-se a força política da classe trabalhadora, na época constituída por milhares e milhares de operários com autonomia profissional, exercendo controle sobre o processo de trabalho e, por isso, responsáveis pelo sucesso ou fracasso de qualquer empreendimento, pois a produção ainda era deles dependente pelo "saber fazer" que monopolizavam. Contestando as condições de trabalho, de salário e de vida, sua orientação política era, de fato, revolucionária, pois lutavam pela reapropriação dos meios de produção sob a influência das ideias marxistas, socialistas e anarquistas. A legislação trabalhista veio conter a agitação política do sindicalismo industrial que se sobrepôs, graças evidentemente ao desenvolvimento industrial, ao sindicalismo de ofício em importância política e numérica, tornando-se um sindicalismo de massas.

No início do século XX, os sindicatos industriais uniram-se a ou fundaram partidos políticos numa clara demonstração de que aceitavam participar do jogo político de acordo com as regras da democracia burguesa que tanto haviam condenado. Vislumbraram na participação das eleições a melhoria de suas condições de vida pela melhoria de suas condições objetivas de trabalho. Por isso, apresentaram reivindicações para obter estabilidade no emprego, aumentos salariais e melhores condições de trabalho. Compreenderam desde logo que a vitória imediata dos movimentos sindicais depende da participação e do envolvimento com a vida política mais ampla e, por essa razão, ao longo do século XX, optaram pela participação na política eleitoral, optando, portanto, pela aceitação das regras do jogo estabelecidas pelas instituições políticas democráticas, organizando-se em partidos social-democratas.

Tratava-se, como ensina Adam Przeworski, “ de ocupar-se da melhora imediata das condições dos trabalhadores" (1989, p. 30), como estratégia elaborada por suas lideranças sindicais e políticas para aglutinar sempre mais trabalhadores em torno dos ideais socialistas aos quais a grande maioria tinha aderido, enquanto perduravam aquelas condições inviabilizadoras da promoção de seus interesses imediatos, isto é, que a eles aderiram como promessa ou possibilidade única de promoção de seus interesses. A intenção dessas lideranças era lutar pelo 

do trabalho segundo o marxismo analítico ou individualismo metodológico

socialismo; a estratégia de luta, a participação no jogo político institucionalizado e o abandono, em consequência, de ações revolucionárias. Acreditou-se, assim, que a participação no jogo político estabelecido seria a arma mais eficiente para a concretização daqueles ideais.

No entanto as lideranças sindicais e políticas dos trabalhadores não conseguiram prever com exatidão a extensão dos resultados da estratégia elaborada e empregada. Se, de um lado, o resultado foi, de fato, a melhoria imediata das condições de vida dos trabalhadores, tal como se esperava, de outro lado, esse mesmo resultado produziu outro não esperado e muito menos desejado, qual seja, o do abandono gradativo, porém constante, dos ideais socialistas pelo conjunto dos trabalhadores, o que de certa forma demonstra, tal como já o havia demonstrado, na década de 60, o trabalho de Goldthorpe e Lockwood, (1968) o caráter de "coletivismo instrumental" da vida sindical: o ideal de transformação social é abandonado em benefício de objetivos limitados às melhorias nas condições materiais imediatas de vida.

E isso porque, participando da vida política em todas as instâncias do poder, a classe trabalhadora dos países industrializados da Europa conquistou, ao longo do século XX, mais e mais direitos pela via da negociação, muito além daqueles previstos nas primeiras legislações trabalhistas, que lhe permitiram desfrutar de uma sensível elevação de seus níveis de vida graças ao ingresso na sociedade de consumo de massa.

Aparentemente paradoxal, é o fato de que a conquista de mais e mais direitos foi obtida durante as sete décadas da predominância do taylorismo/fordismo como formas de organização do processo de trabalho, responsáveis pela desprofissionalização da grande massa de trabalhadores, agora trabalhadores especializados na execução de uma ou mais tarefas simplificadas, repetitivas e insignificantes, pensadas pela gerência científica, inclusive nos gestos e movimentos necessários para realizá-las bem e rapidamente.

A desprofissionalização, isto é, a especialização, conduz inexoravelmente à perda da noção da totalidade do processo de produção e da prestação de serviços e compromete a capacidade de compreensão do significado do próprio trabalho. É causa de profunda insatisfação e profundo sentimento de frustração por impossibilitar a realização das potencialidades intelectuais e a satisfação das necessidades de autoestima e autorrealização, raiz da tendência ao absenteísmo, desperdício de material, negligência, acidentes de trabalho, turnover (rodízio de pessoal), alcoolismo, drogas, stress, Ler (lesão por esforço repetitivo, fadiga constante etc. Em outras palavras, a desprofissionalização significa a degradação do trabalho por significar a monopolização do saber pela gerência científica, cujo programa, nas palavras de Benjamin Coriat:

$\{\ldots\}$ se define pela análise do obstáculo que vence: trata-se nada menos que de expropriar aos trabalhadores seu saber $\{. .$.$) não se trata somente de expropriar aos trabalhadores$ seu saber, senão também de confiscar este saber recolhido e sistematizado - em benefício exclusivo do capital $\{. .$.$\} o que aqui se instaura maciçamente é a separação$ entre trabalho de concepção e de execução, um dos momentos-chave da separação entre trabalho manual e intelectual (CORIAT, 1976, p. 94). 
A monopolização do saber pela gerência científica reduz o poder de barganha da classe trabalhadora, agora, na sua grande maioria, simples apêndice da máquina, sem qualquer controle sobre o processo de trabalho, mera cumpridora de ordens emitidas pela gerência científica, cujos membros, sem escolaridade e sem qualificação profissional, eram substituídos com muita facilidade.

Nessas condições, como reagir? Afirmar que a classe trabalhadora assiste passivamente ao seu próprio massacre é desconhecer as suas práticas reativas efetivas ou propositadamente desvirtuar a história, como alguns autores:

\begin{abstract}
A tecnologia capitalista e a divisão capitalista do trabalho não se desenvolveram, portanto, em razão de sua eficácia produtiva, considerada em si mesma, mas em razão de sua eficácia no contexto do trabalho alienado e forçado, isto é, de um trabalho sujeito a um fim que lhe é estranho. As técnicas capitalistas não visavam maximizar a produção e a produtividade em geral de quaisquer trabalhadores, foram concebidas para maximizar a produtividade para o capital de trabalhadores que não tinham nenhuma razão para colaborar nisso, dados os fins de sua produção lhes serem ditados por uma vontade inimiga. Para os obrigar a vergar-se a esta vontade, era preciso que perdessem não apenas a propriedade dos meios de produção, mas também, em toda a medida do possível, o controle do funcionamento desses meios; isto é, o poder feito de habilidade, de conhecimentos profissionais, de savoir faire - de assegurar o funcionamento das máquinas por si próprios, sem o concurso de um enquadramento hierárquico composto de engenheiros, de técnicos, de profissionais de manutenção, de preparadores, etc., de todo um gênero de pessoas que, tecnicamente, a fábrica poderia dispensar, mas cuja função política é perpetuar a dependência dos operários, a sua subordinação, a sua separação dos meios e do processo de produção (GORZ et al., 1973, p. 89-90).
\end{abstract}

Assim, manipulados e "vergados à vontade inimiga do capital" - essa entidade abstrata e, por isso mesmo, todo poderosa - os trabalhadores, segundo aquelas interpretações, estariam submetidos passivamente aos seus imperativos implacáveis e ele, o capital, iria impondo os seus desígnios sem encontrar empecilho ou resistência inteligente para arrefecer-lhe a fúria. Apesar de serem capazes de reconhecer que "não tinham nenhuma razão para colaborar nisso", seriam incapazes de agir porque, de fato, teriam se tornado marionetes da história à espera de redenção eterna pelas mesmas condições objetivas estruturais que os subjuga.

E isso não é verdade. Basta acompanhar a história dos movimentos operários para negar o poder das determinações estruturais na configuração das unidades de trabalho, e logo se compreenderá que os trabalhadores jamais se submeteram passivamente aos imperativos da organização do processo de trabalho tal como desejaria o capital. Reagem e reagem rápida, inteligente e eficazmente a todas as situações e condições de trabalho que contrariem seus interesses imediatos, obrigando a que se proceda a um conjunto de modificações no interior das unidades de trabalho que atendam, pelo menos parcialmente, aos seus interesses, como resposta ao enfrentamento permanente e manifesto entre capital e trabalho, do qual nem sempre se impõe a vontade inimiga do capital. Ao contrário. O capital se vê obrigado a fazer concessões se 

do trabalho segundo o marxismo analítico ou individualismo metodológico

quiser obter o consentimento e, daí, a colaboração necessária do trabalhador. E a natureza dessas concessões dependerá da interveniência maior ou menor de outros fatores, além do confronto permanente e direto entre capital e trabalho no interior das unidades de produção e de prestação de serviços, mas certamente concessões serão feitas.

Exemplos significativos do poder permanente dos trabalhadores se revelam nas alterações das relações entre chefias, supervisores e trabalhadores do chão de fábrica e do chão dos escritórios que perderam o conteúdo autoritário; nas mudanças das condições de trabalho que lhes favoreceram na realização do trabalho (ritmo de trabalho, segurança, higiene, poluição); no estabelecimento de benefícios aos empregados (seguros de vida, plano de financiamento e convênios médico-odontológicos, nos programas de alimentação e transportes); na definição de um quadro de carreira que garanta promoções, etc. em todos os países industrializados do Ocidente, inclusive no Brasil. Considerem-se também as práticas mais contundentes de resistência dos trabalhadores às condições objetivas de trabalho: o absenteísmo, o turnover, a negligência, o desperdício de material, os acidentes de trabalho, a sindicalização em massa, etc. etc., e, evidentemente, as comissões de trabalhadores - comissões de fábrica e comissões de funcionários dos escritórios - expressão do movimento mais amplo de resistência dos trabalhadores que permite a representação e a defesa efetiva dos interesses dos trabalhadores no seu dia a dia de trabalho, superando as intervenções sindicais.

As reivindicações apresentadas nessas comissões expressam o modo de elaboração da percepção e do desenvolvimento da compreensão da própria condição assalariada, num processo, já denominado por Thompson (1978), de "autoconfecção" de formação de classe por considerar a subjetividade do trabalhador como elemento decisivo na determinação de suas práticas. Além disso, as comissões de fábrica e dos trabalhadores de escritório são capazes de resolver parte substantiva dos problemas cotidianos dos trabalhadores e, ao mesmo tempo, indicar para a direção das empresas os problemas humanos que afetam a produção e a prestação de serviços. Por isso, confirmam a tese segundo a qual a configuração do interior das unidades de trabalho é, de fato, fruto dos ajustamentos e rearranjos decorrentes do enfrentamento entre as partes, isto é, de um consentimento sem o qual o processo de submissão do trabalho ao capital não pode se efetivar, a não ser que se parta do pressuposto da total incapacidade de raciocínio e de ação racional dos trabalhadores na defesa de seus interesses, o que é absolutamente inimaginável e negado pelo processo histórico.

Assim, e apesar da degradação da qualidade do trabalho provocada pelo taylorismo/ fordismo, essas formas de organização do processo de trabalho fizeram surgir novas formas de resistência dos trabalhadores, além da greve, e assistiram ao fortalecimento dos sindicatos - devido à enorme quantidade de empregos que geraram -à elevação dos salários diretos e indiretos, graças à conquista de muitos benefícios sociais, e à melhoria das condições materiais de trabalho e de vida da maioria dos trabalhadores, agora não só produtores, mas também consumidores na economia de produção padronizada em massa. 


\section{A reestruturação produtiva dos anos 70 e 80 e a resistência dos trabalhadores}

As tecnologias da informação, conjugadas às novas técnicas gerenciais do processo de trabalho, transformaram o interior das fábricas e dos escritórios, imprimindo-lhes uma nova face e deram origem a uma nova forma de organização do trabalho denominada toyotismo, pois foi elaborada e implementada por Eiji Toyoda e Taiichi Ohno, no Japão. Suas principais características são:

- Redução das dimensões físicas das unidades empresariais em virtude não só do desenvolvimento do processo de terceirização da produção, isto é, da formação de redes empresariais, como também da adoção dos métodos japoneses de organização do interior das unidades produtivas para maior racionalização na utilização dos recursos e, sobretudo, para o rígido controle dos estoques que deu origem ao método just-in-time ou produção sem estoques;

- Diminuição da estrutura de autoridade hierárquica com o surgimento de equipes multifuncionais, com versatilidade em várias tarefas e compreensão da totalidade do processo de produção com autonomia para a tomada de decisões operacionais;

- Redução dos postos de trabalho, já que a nova lógica organizacional se fundamenta nas tecnologias de informação de base microeletrônica e, portanto, nos princípios de integração e supervisão de todo o sistema de produção;

- Controle de qualidade a cada etapa do processo produtivo para se chegar ao controle da qualidade total, com zero de defeitos e drástica redução do desperdício;

- Fim, portanto, da execução de tarefas parcelares, simplificadas e repetitivas, exigindose dos trabalhadores capacidade de compreensão da totalidade do processo de trabalho, versatilidade em várias tarefas, rápida adaptação às inovações e precisão na tomada de decisões, uma vez que os novos princípios de gestão enfatizam o processo e não a estrutura e a função;

- Forte envolvimento de todos os trabalhadores em todas as etapas do processo de trabalho, tendendo a permitir o fim da total dissociação entre gerência científica e o chão de fábrica e do escritório que caracterizou as formas taylorista e fordista de organização do trabalho;

- Adoção do princípio de aperfeiçoamento contínuo do processo (kaizen, palavra japonesa que significa aperfeiçoamento contínuo), encorajando, assim, os trabalhadores ao desenvolvimento e à utilização de suas potencialidades, isto é, inteligência, criatividade, espírito crítico e iniciativa, em todas as etapas da produção e/ou da prestação de serviços. Assim, foi possível vislumbrar-se aí o início de um novo processo, o da reumanização do trabalho, degradado pela universalização do taylorismo e fordismo no século XX. Os círculos de controle da qualidade, conhecidos como "CCQS", nos quais se discutem melhorias no processo de produção, são a expressão mais significativa desse princípio;

- Produção orientada pela demanda, ao contrário da produção padronizada em massa do fordismo, o que implica conhecimento das tendências do mercado para atender o consumidor que exige variedade e diversificação na oferta de produtos e serviços. Por isso, a necessidade 

do trabalho segundo o marxismo analítico ou individualismo metodológico

de produzir uma diversidade de produtos em pequenos lotes e o sistema just-in-time/kanban. (LAZZARESCHI, 2008, p.101-102)

Nocontexto da globalização daeconomia, cuja consequência imediata é o recrudescimento da competição entre empresas, regiões e países, a reestruturação produtiva se impõe como fator importante para o seu enfrentamento e suas implicações sociais atingem todos os trabalhadores sem distinção, pelas seguintes razões:

- Esgotamento relativo do paradigma taylorista/fordista por sua comprovada ineficiência produtiva, isto é, por sua rigidez tecnológica e organizacional que inviabiliza a inovação de produtos com sua produção padronizada em massa;

- Instabilidade dos mercados, cuja consequência era a necessária adaptação da produção ao dinamismo da demanda, agora assentada na exigência de qualidade dos produtos e nos humores dos consumidores, o que, em parte, define as conjunturas econômicas, nacionais e internacionais;

- Aparecimento de novos padrões de consumo a exigir inovação de produtos;

- Redução considerável dos postos de trabalho, como acima já indicado, que resulta do rígido controle dos procedimentos operacionais para a eliminação de unidades repetitivas ou ineficientes;

- Desestruturação dos mercados de trabalho com a terceirização nacional e internacional da produção e da prestação de serviços, como, por exemplo, os serviços de informática;

- Desenvolvimento do sentimento de insegurança dos trabalhadores, continuamente ameaçados de desemprego seja pelas inovações tecnológicas, seja pelas novas técnicas de gerenciamento do processo de trabalho que dão origem à regulamentação de novas e precárias relações de trabalho, como o trabalho em regime de tempo parcial, o contrato temporário de trabalho, a terceirização, o contrato de prestação de serviços, o banco de horas, o trabalho em domicílio, seja pelas conjunturas econômicas nacionais e internacionais:

- Concentração do poder sem centralização do poder, tal como se refere Sennet (1999, p. 64) sobre a fragmentação do processo de trabalho com a formação de redes empresariais sob o comando estrito concentrado na grande corporação que decide não só o quê, como, quando, quanto e onde produzir, mas também fixa metas de produção de difícil cumprimento, cuja consequência é a intensificação do trabalho nas empresas dependentes da sua substituição na rede;

- Exigência de novos saberes, quase sempre adquiridos nos bancos escolares, e de qualidades intelectuais, mentais, culturais, sociomotivacionais da pessoa do trabalhador para lhe permitirem a compreensão da totalidade do processo de trabalho, a versatilidade em várias tarefas, a capacidade de tomar decisões rápidas e corretas e a participação em equipes multifuncionais.

Essa nova lógica organizacional tornou muito mais difíceis as condições de trabalho e, sobretudo, dos mercados de trabalho que, por suas imposições, fizeram surgir o conceito de 
empregabilidade para referir-se à capacidade de candidatar-se a um emprego ou à capacidade de manter-se empregado, dadas as frequentes transformações do mundo do trabalho a exigir sempre novas competências profissionais.

Nessas condições, os sindicatos perdem poder de barganha, que se expressa na qualidade dos acordos trabalhistas e níveis salariais conquistados. As reivindicações que apresentavam, na verdade, reduziram-se a uma só: a defesa do emprego. De combativos ao longo do século passado, organizando movimentos grevistas de confronto aberto ao capital, com os quais reivindicavam aumentos salariais, diminuição da jornada de trabalho, aposentadoria plena, participação efetiva na elaboração de políticas públicas para a melhoria das condições de trabalho e de vida de todos os trabalhadores, os sindicatos passaram a adotar uma nova orientação: a da negociação permanente seja entre empresa e empresa, seja por setor, seja articulada entre governo x sindicato $\mathrm{x}$ empresários na tentativa de garantir alguma estabilidade dos empregos.

Leôncio Martins Rodrigues (1999) e José Pastore (1994) chamaram a nossa atenção sobre as razões das transformações do sindicalismo na Europa e nos Estados Unidos e apontaram os mesmos fatos: $1^{\circ}$ ) o declínio da densidade sindical; $2^{\circ}$ ) o enfraquecimento do poder dos sindicatos; $3^{\circ}$ ) a descentralização da negociação e flexibilização das relações de trabalho, isto é, na contratação, descontratação e remuneração da força de trabalho; $4^{\circ}$ ) o fortalecimento das negociações na empresa, como expressões das formas de adaptação às novas condições impostas pela globalização da economia e, fundamentalmente, pela competição.

Assim, o processo de modernização tecnológica e organizacional das empresas afetava a orientação política dos sindicatos e provocava mudanças muito significativas no comportamento, discurso e reivindicações dos trabalhadores remanescentes nas unidades de trabalho. Os trabalhadores compreenderam que a sua sobrevivência no emprego dependia da sobrevivência das empresas onde trabalhavam, cujo sucesso estava inextrincavelmente ligado aos altos índices de produtividade e qualidade dos produtos. E, da mesma maneira, as empresas compreenderam que a sua sobrevivência dependia do tipo de parceria que estabelecesse com o trabalhador, o que significava permitir a participação não só nas decisões operacionais como também nos lucros obtidos pelo aumento de produtividade, a partir da fixação, em conjunto, das metas a se realizar, além da adoção do sistema formal de remuneração variável que, como o próprio nome o indica, vincula o montante da remuneração à produtividade das equipes de trabalho.

Remuneração variável e participação nos lucros alteram as relações de trabalho e rompem a relação salarial, isto é, "o conjunto das condições jurídicas e institucionais que regem o uso do trabalho assalariado, como também a reprodução da existência dos trabalhadores" (BOYER, 1986, p. 18), justificando, em parte, a flexibilização e/ou desregulamentação dos mercados de trabalho. A relação salarial, desse modo, passou a se estabelecer com a capacidade de produção das empresas determinada pela tecnologia empregada; a eficiência do conjunto de seus trabalhadores; a qualidade do produto; a competência para a inovação dos processos e dos produtos e, sobretudo, a capacidade de administração dos negócios que, juntos, definem a 

do trabalho segundo o marxismo analítico ou individualismo metodológico

capacidade de competir no mercado nacional e internacional e, em decorrência, a obtenção de lucros, garantindo, ao mesmo tempo, a manutenção do emprego e a elevação dos salários ou a participação nos lucros, que supõe o desenvolvimento de novas estruturas organizacionais e de gestão do pessoal.

Ora, a participação nos lucros interessava, como sempre interessa, tanto à empresa quanto aos trabalhadores. Para a empresa, significa garantir o esforço dos trabalhadores para atingir as metas estabelecidas, evitando paralisações, greves ou produção defeituosa por negligência ou irresponsabilidade. Significa também desmobilizar o movimento sindical, na medida em que os interesses dos trabalhadores, agora parceiros ou sócios do capital, estariam interligados aos interesses de sua empresa e sua realização não mais dependeria das conquistas dos trabalhadores do seu setor ou dos trabalhadores em seu conjunto. Em consequência, o movimento sindical perde importância para esses trabalhadores ou deixa de ter sentido como estratégia para a promoção de seus interesses econômicos imediatos, pessoais ou coletivos.

E dessa compreensão surgia uma nova tendência: a integração do trabalhador à empresa, num processo de explícita colaboração entre as partes. Apesar do reconhecimento da importância das novas tecnologias na sua determinação, há de se tratá-la como resultado de um conjunto de fatores econômicos, políticos, sociais e culturais interligados e, sobretudo, como fruto de ações estratégicas nas condições dadas, cujas consequências atingiram em cheio o coração da vida sindical.

\begin{abstract}
As novas relações de trabalho estão conduzindo os sindicatos a uma encruzilhada. A globalização e as modernas tecnologias levam as empresas a atraírem seus empregados para bem junto de si, remunerando-os por produção, qualidade e comprometimento. Afinal, os trabalhadores têm de participar ativamente dos processos produtivos para ajudar as empresas a vencerem a competição. Nesse sentido, as empresas acabam competindo com os sindicatos, passando a prestar os serviços que os empregados, até então, iam buscar no sindicato. $\mathrm{O}$ sindicato moderno está à procura de um novo rumo. Afinal, os métodos de produzir mudaram radicalmente. As empresas estão sendo forçadas a lançar produtos novos com muita velocidade. Há cinco anos, uma novidade industrial (enquanto novidade), durava dois anos. Em 1993 durava apenas seis meses. No campo da eletrônica, seis semanas (WEF, 1992). O ritmo de criação e de obsolescência é frenético. Vencer, nesse ambiente, exige muito mais diálogo do que confrontação (Keckscher, 1988); muito mais flexibilidade do que rigidez; mais aproximação do que distanciamento. Tudo isso tem fortes implicações para o tipo de sindicalismo do próximo século (PASTORE, 1992, p. 51).
\end{abstract}

Assim, e apesar da legislação em vigor, teve início, também no Brasil, o desenvolvimento das negociações diretas, pela via de acordos e convenções coletivas, num prenúncio da flexibilização do mercado e das relações de trabalho, ainda sob a proteção e o patrocínio do Estado. A relação de confrontação foi substituída pela efetivação de um compromisso de responsabilidade mútua que resulta das novas formas de administração das empresas que, por sua vez, sugerem o envolvimento estreito de todos os seus trabalhadores na árdua tarefa de 
garantir-lhes a sobrevivência, a partir da liberação de informações sobre o seu desempenho, a sua situação de mercado, os seus planos futuros, etc.

No interior das empresas, os trabalhadores remanescentes logo perceberam que os limites de seu poder foram ampliados comparativamente à fase taylorista e fordista de organização do processo de trabalho, pois compreenderam que as empresas haviam se tornado muito mais dependentes do que nunca foram da estreita colaboração de seus trabalhadores. E para manter essa colaboração, evitando-se o absenteísmo, o turnover, a negligência, a irresponsabilidade consciente ou inconsciente, as empresas se viram obrigadas a fazer concessões. E passaram a oferecer altos salários, formação profissional, promoções no quadro de carreira, benefícios sociais que correspondiam a verdadeiros salários, como bolsa-educação, fundo de pensão, clube esportivo, colônia de férias, programas de qualidade de vida no trabalho, além de se anteciparem às reivindicações de seus trabalhadores. Ressalte-se também o fato de que trabalhadores mais capacitados tendem a negociar individualmente suas condições de trabalho e de salário, pois salários e benefícios coletivos padronizados não expressam o reconhecimento pela aquisição das novas competências profissionais, adquiridas e atualizadas sobretudo nos bancos escolares e nos cursos de formação sempre mais sofisticados.

São muito os autores que compartilham dessas análises sobre o comportamento sindical dos trabalhadores na atualidade e sobre as dificuldades dos sindicatos na manutenção de seu papel tradicional de representação e de defesa expressa de seus interesses.

Entre os fatores de debilitamento da solidariedade dos trabalhadores estão a dispersão da produção (às vezes por países diferentes e distantes), a redução da dimensão das unidades de fabricação e o aumento da produção em pequenas empresas; a maior mobilidade do capital internacional; a tendência em direção a acordos por empresas e locais de fabricação; a flexibilização da produção, das normas e regulamentos que regiam tarefas, hierarquias e carreiras dos empregados, a maior heterogeneidade da força de trabalho em virtude do aparecimento de novas profissões, da maior presença da mulher e dos imigrantes no conjunto da mão-de-obra. O resultado desses novos desenvolvimentos não é apenas o fim (ou o começo do fim) do velho modelo tayloristafordista, mas também, como dificilmente poderia deixar de ser, da velha classe operária sobre a qual se apoiara o sindicalismo como fenômeno de massa (RODRIGUES, 1999, p. 177).

São afirmações que se repetem em numerosos outros textos, como, por exemplo, no volume I do livro de Manuel Castells (2011, p. 350) "A Era da Informação: Economia, Sociedade e Cultura", no artigo de Iram Jácome Rodrigues, "Sindicalismo, emprego e relações de trabalho na indústria automobilística" (1997) e no artigo a seguir:

Para onde foram os sindicatos? Esse é o tema proposto para esse dossiê. Nossa resposta à hipótese apresentada no início deste artigo é que as últimas décadas parecem empurrar o novo sindicalismo em direção a uma esdrúxula combinação, síntese de, ao menos, três movimentos: a velha prática peleguista, a forte herança estatista e a forte 

do trabalho segundo o marxismo analítico ou individualismo metodológico

influência do ideário neoliberal (ou social-liberal), impulsionada, ainda, pelo culto da negociação e defesa do cidadão. Vale dizer que cada um destes elementos pode ter prevalência em diferentes conjunturas (ANTUNES; SILVA, 2015, p. 525).

\section{A Quarta Revolução Tecnológica: a inteligência artificial e o movimento dos trabalhadores}

O surgimento de novas formas de execução do trabalho em todos os setores da vida econômica - graças à utilização da inteligência artificial, blockchain, big data e profusão de aplicativos para a satisfação de um sem número de necessidades sociais -, inaugura a quarta revolução que dá origem a uma nova reestruturação produtiva e organizacional ao transformar radicalmente uma vez mais os mundos do trabalho no curto espaço de tempo de meio século, considerando-se o toyotismo como organização do processo de trabalho implementada a partir dos anos 70 e 80 do século passado e que hoje começa a ser ultrapassada devido ao desenvolvimento das tecnologias de informação, de comunicação e de inteligência.

Essa nova e verdadeira revolução na organização do processo de trabalho parece intensificar todas as consequências sociais da reestruturação produtiva dos anos 70 e 80 acima apontadas, tal como tem se apresentado nesta fase inicial de sua implementação nos países mais industrializados do mundo e mesmo aqui entre nós

Em 2017 e 2018, dois acontecimentos envolvendo os trabalhadores brasileiros chamaram a atenção de todos: o primeiro foi a aprovação da reforma da Consolidação das Leis do Trabalho - CLT - em 13 de julho de 2017, sem que fossem registrados protestos da massa dos trabalhadores. Os protestos públicos contra a reforma da CLT contaram apenas com a presença dos partidos de esquerda e dos partidos de oposição ao governo federal, de todos os sindicatos e de todas as centrais sindicais, unidas naquele momento para a defesa da manutenção da contribuição sindical obrigatória, ameaçada pela reforma, e sem a qual fica comprometida a própria manutenção dos sindicatos e das centrais, uma vez que a grande maioria dos trabalhadores brasileiros não é sindicalizada e, portanto, não contribui espontaneamente para a manutenção dos sindicatos.

Além disso, a proposta de prevalência dos acordos coletivos sobre o legislado e a permissão para celebrar acordos individuais aos trabalhadores com curso superior e salário duas vezes maior que o teto do INSS - Instituto Nacional de Seguridade Social - reduziriam, de fato, o poder dos sindicatos, pois a partir da aprovação da reforma estaria definitivamente reconhecida a suficiência, isto é, a capacidade intelectual dos trabalhadores para lutar pela defesa de seus interesses individuais e coletivos pela via da negociação coletiva permanente.

A grande maioria dos trabalhadores brasileiros permaneceu à margem do processo de discussão do projeto de reforma, por ter compreendido que a reforma não lhes retirava direitos fundamentais e, ao mesmo tempo, apenas ampliava as suas possibilidades de contratação e de negociação direta com os empresários e, por isso, não se manifestou maciçamente como esperavam os líderes sindicais. Além disso, muitas propostas da reforma, como algumas das 
"novas" relações de trabalho, não eram mais novidade: estava de fato em vigor, graças à tendência de o negociado se sobrepor ao legislado desde a primeira década deste século. Aceitar a reforma foi a decisão estratégica dos trabalhadores brasileiros nas novas condições de trabalho.

O segundo fato que chamou a atenção de todos os brasileiros foi a rápida, eficaz, eficiente e direta mobilização dos caminhoneiros, em maio de 2018, sem a intervenção do sindicato. As tecnologias da informação, mais precisamente, o WhatsApp, isto é, esse poderoso meio de comunicação entre as pessoas, permitiu a mobilização dos caminhoneiros para uma greve que durou mais de dez dias e que só chegou ao fim com a celebração de um acordo muito vantajoso para essa categoria profissional. A greve demonstrou que os trabalhadores não são hipossuficientes e, por isso, podem dispensar a intermediação das lideranças sindicais, muitas vezes mais voltadas para a defesa de seus interesses pessoais do que para a defesa das diferentes categorias profissionais, sobretudo interessadas na manutenção da estrutura sindical brasileira que muito lhes favorece e que não foi estabelecida pelos próprios trabalhadores.

Esses dois marcantes acontecimentos demonstram que, dentre todas as transformações econômicas, políticas, sociais e culturais que tipificaram as últimas décadas do século passado e o início do século 21, a mais significativa para a classe trabalhadora brasileira refere-se, sem sombra de dúvida, ao seu acesso à educação escolarizada e aos meios de comunicação de massa, especialmente à mídia eletrônica, cuja consequência é, inevitavelmente, o desenvolvimento da consciência política para exigir participar livre e soberanamente da determinação dos rumos de sua própria história, sem a intermediação daqueles que nem sempre a defenderam como deveriam.

O ano de 2020 teve início com números muito significativos sobre a recuperação econômica do país, graças à política de ajuste fiscal, às reformas da CLT e da Previdência Social, e à pauta de continuidade de reformas prometidas pelo Congresso Nacional, principalmente a reforma tributária, que permitiram vislumbrar uma rápida e sustentada redução dos índices de desemprego com a expectativa fundamentada no sucesso das medidas econômicas em curso, cujas consequências seriam o aumento dos investimentos em todos os setores da economia, o apoio à pequena e média empresa, o incentivo ao empreendedorismo, a abertura da economia brasileira, a conquista de grandes mercados internacionais etc. etc.

No entanto a perspectiva de recuperação da economia brasileira durou apenas os dois primeiros meses do ano novo, pois os casos de contaminação social pelo novo coronavírus começaram a proliferar e provocaram a paralisação de quase todas as atividades, cujas consequências em todas as dimensões da vida social são de extraordinária gravidade: a queda do PIB em mais de 5\%, a elevação dos índices de desemprego, a impossibilidade de obtenção de renda para milhões de trabalhadores informais, o enorme desajuste fiscal para subsidiar o orçamento ou economia de guerra, uma decisão necessária para garantir, pelo menos temporariamente, a sobrevivência do maior número. 

do trabalho segundo o marxismo analítico ou individualismo metodológico

Como planejar o futuro neste momento de cruel excepcionalidade para todos, sobretudo para milhares de famílias enlutadas e pais desesperados pela impossibilidade de manter o sustento de seus filhos? Passado o auge da pandemia, como enfrentarão os trabalhadores a trágica situação econômica, política, social por ela provocada? Segundo a perspectiva teórica que fundamenta este artigo, os trabalhadores brasileiros, como os trabalhadores do mundo inteiro atingidos pela crise sanitária, saberão, uma vez mais, tomar as rédeas do rumo da própria história com a escolha de alternativas que considerarem as melhores para si.

\title{
Considerações Finais
}

Procurou-se aqui compreender as atitudes e o comportamento dos trabalhadores face às mudanças do mundo do trabalho de uma perspectiva teórica que permitisse acompanhar a ação dos sujeitos da história não como meros reflexos das determinações estruturais ou ainda como simples manifestações, já previstas, de suas posições no processo de produção capitalista, mas como expressões da capacidade de homens e mulheres de tomarem decisões racionais, de acordo com os seus interesses e motivações, nas circunstâncias dadas, de modo a possibilitar o estabelecimento do nexo entre subjetividade/objetividade, isto é, entre consciência e ação.

\begin{abstract}
As relações sociais constituem as estruturas com base nas quais os agentes, individuais e coletivos, deliberam sobre objetivos, percebem e avaliam alternativas e selecionam linhas de ação. Como corolário, repetirei $\{\ldots . .$.$\} que as relações sociais devem ser, elas$ próprias consideradas um resultado historicamente dependente, para usar mais uma vez a frase de Marx, "das ações recíprocas dos homens." Vale dizer, embora as relações sociais constituam uma estrutura de escolhas segundo a qual os agentes fazem sua opção, essa opção pode ser alterar as relações sociais. Estas não são independentes das ações humanas. Não é neste sentido que são "objetivas". São objetivas, indispensáveis e independentes da vontade individual apenas no sentido de constituírem as condições sob as quais as pessoas lutam sobre transformar ou não suas condições (PRZEWORSKI, 1989, p. 118).
\end{abstract}

Assim, passou-se a compreender a estrutura social como resultado ou produto das ações dos sujeitos - homens e mulheres - na história, que a constroem a partir de um processo de avaliação racional das possibilidades existentes para a realização de seus interesses, isto é, que a constroem como estratégia. Ao mesmo tempo, compreende-se que a dramaticidade da condição humana nasce da experiência reveladora da própria incapacidade de prever a totalidade das consequências das escolhas efetivadas e da capacidade de errar na avaliação das consequências previstas. Fazer história significa, portanto, ter de enfrentar desafios inevitáveis à inteligência.

\section{Referências}

ANTUNES, Ricardo; SILVA, João Batista da. Para onde foram os sindicatos? Do Sindicalismo de confronto ao sindicalismo negocial. Caderno CRH, Salvador, v. 28, n. 75, p. 511-527, set./dez. 2015. 
BOYER, Robert. La Flexibilité em Europe. Paris: La Découverte, 1986.

CASTELLS, Manuel. A Era da Informação: economia, sociedade e cultura. A Sociedade em Rede. São Paulo: Paz e Terra, 2011. $1 \mathrm{v}$.

COHEN, Gerald. Karl Marx's Theory of History. A Defense. Oxford: Claredon Press, 1978.

CORIAT, Benjamin. Ciencia, Tecnica y Capital. Madrid: H. Lume Ediciones, 1976.

ELSTER, Jon. Marx Hoje. Rio de Janeiro: Paz e Terra, 1989.

GOLDTHORPE, John Harry et al. The affluent worker: industrial attitudes and behavior. Cambridge: University Press, 1968.

GORZ. Andre et al. Divisão Social do Trabalho e Modo de Produção Capitalista. Lisboa: Publicações Escorpião, 1973.

HOBSBAWM, Eric. Labouring Men. Studies in the history of labour. New York: Basic Books. Inc., Publisher, 1964.

LAZZARESCHI, Noêmia. Sociologia do Trabalho. Curitiba: IESDE; Brasil S. A., 2008.

OLSON, Mancur. The logic of collective action: public goods and the theory of groups. New York: Schoken Books, 1968.

PASTORE, José. Relações de Trabalho em Economias Competitivas. In: VELLOSO, João Paulo dos Reis; RODRIGUES, Leôncio Martins. (org.). O futuro do sindicalismo. Cut, Força Sindical, CGT. São Paulo: LTR, 1992.

PASTORE, José. Flexibilização dos Mercados de Trabalho e Contratação Coletiva. São Paulo, LTr, 1994.

PRZEWORSKI, Adam. Capitalismo e social-democracia. São Paulo: Companhia das Letras, 1989.

RODRIGUES, Iran Jácome. Sindicalismo, emprego e relações de trabalho na indústria automobilística. In: ANTUNES, Ricardo. (org.). Neoliberalismo, trabalho e sindicatos. Reestruturação produtiva no Brasil e na Inglaterra. São Paulo: Boitempo Editorial, 1997.

RODRIGUES, Leôncio Martins. Destino do sindicalismo. São Paulo: Editora da USP/FAPESP, 1999.

ROEMER, John. Analytical marxism. Cambridge: Cambridge University Press, 1986.

SENNETT, Richard A corrosão do caráter: consequências do trabalho no novo capitalismo. Rio de Janeiro; São Paulo: Record, 1999.

THOMPSON, Eric Paul. A miséria da teoria ou um planetário de erros. Rio de Janeiro: Zahar Editores, 1978. 